\title{
COFRADÍAS Y GREMIOS DE NAVARRA EN LA ÉPOCA DE CARLOS III
}

\author{
POR \\ InMACULADA ARIAS DE SAAVEdRA \\ Miguel LUIS LÓPEZ MuÑoz \\ Universidad de Granada
}

\section{RESUMEN}

En 1770 la administración central realizó en toda España una gran encuesta para conocer el número de cofradías religiosas, sus medios económicos, actividades que realizaban, etc., con el fin de acabar con ciertas prácticas contrarias a sus constituciones y reducir su número. Utilizando la información de esta encuesta, se realiza aquí un estudio de las cofradías del reino de Navarra. Las advocaciones de las cofradías, los lugares donde tenían su sede, la aprobación por las autoridades eclesiásticas y civiles de que gozaban y su situación económica son analizadas, prestando especial alención a las cofradías gremiales de la ciudad de Pamplona.

\begin{abstract}
In 1770 the central administration carried out an inquiry all over Spain so as to get to know the number of religious brotherhoods, their economic means, and their activities. This was intended in order to do away with certain practicies contrary to their constitution. Another goal was to reduce the number of religious brotherhoods. This paper uses the information cantained in the inquiry and studies the brotherhoods within the kingdom of Navarra. The study focusses upon their devotions, their sees, the approvals by civil and religious authorities, and their economic staus, special attention is drawn to guild fraternities in the city of Pamplona.
\end{abstract}

Las cofradías son un movimiento asociativo de fieles, que constituye una de las manifestaciones más importantes de la religiosidad popular. En España,

El asociacionismo en la jglesia Hispania Sacra 50 (1998) 
ésta no podría entenderse sin las cofradías, dado su número y diversidad. Hasta el momento no tenemos estudios de conjunto que permitan conocer con suficiencia este fenómeno, particularmente en la Edad Modema'. El Expediente General de Cofradias abierto por la administración borbónica durante el reinado de Carlos III constituye una fuente privilegiada, la más completa a nivel nacional para un estudio de conjunto que permita evaluar el fenómeno a finales del Antiguo Régimen ${ }^{2}$. La utilización de su abundantísima documentación ha sido parcial. En la actualidad, y gracias a un Proyecto subvencionado por la DGICYT del MEC, estamos realizando un estudio general del Expediente ${ }^{3}$. En este trabajo ofrecemos un adelanto del estudio y las conclusiones en el terreno navarro.

La elaboración de este expediente se inscribe dentro del proceso de intervención estatal en el ámbito religioso, que caracteriza la política regalista del periodo, de afirmación de la autoridad regia frente a Roma y de reforma de la religiosidad barroca de la gran mayoría de los súbditos, dentro de una corriente religiosa imbuída de ciertos tintes jansenizantes y defensora de una espiritualidad más interiorizada y menos ritualista.

La intervención del poder civil perseguía la regulación de la situación jurídica de las cofradías, mediante la aprobación de sus ordenanzas o estatutos por el Consejo de Castilla — sustrayéndolas del control eclesiástico y de la influencia de las órdenes mendicantes- y la reorientación de sus funciones exclusivamente hacia el culto religioso, limitando sus significaciones sociales y sus fines asistenciales, campo que pretendía asumir la administración pública.

Aunque la mayoría de los argumentos aducidos para su reforma son de carácter espiritual, la preocupación subyacente era de índole económica y políti-

1 El cstudio de las cofradías, en general bastante infravalorado, se inició centrado en los aspectos benéfico-institucionales (vid. A. RUMEU DE ARMAS, Historia de la previsión social en España. Cofradias, Gremios, Hermandades, Montepíos, Barcelona, 1981, 1ª ed. en Madrid, 1944) o con perspectivas excesivamente locales. En los últimos años se ha beneficiado del impulso dado por la Historia de las Mentalidades y ha encontrado su lugar idóneo dentro del estudio de la religiosidad popular (vid. un planteamiento general para el siglo XVIII en A. MESTRE SANCHís, Religión y cuitura en el siglo XVII cspañol: La Iglesia en la España de los siglos XVII y XVIII, vol. IV de R. GARCí VILloslada (dir.), Historia de la Iglesia en España, Madrid, 1979, pp. 583-743). No es éste el lugar para hacer una referencia bibliografica completa del terna, pero mercce destacarse la celebración de congresos o la creación de una sección específica para el mismo en revistas especializadas como Hispania Sacra. En el ámbito local, se conocen bien las cofradias de Sevilla, Granada, Murcia, Valladolid, Cantabria, Asturias, Burgos...

2 Son diecisicte legajos conservados en el A.H.N., Consejos, legs. 7090 a 7106 . Su contenido está enunciado cn M. ROMERo SAMPER, El Expediente General de Cofradias del Archivo Histórico Nacional. Regesto documental: Hispania Sacra, 40 (1988) 205-234.

3 Las bases metodológicas del proyecto se desarrollan en la comunicación: 1. ARIAS DE SAAVEDRA y M. L. LÓPEZ MUÑOZ, El Expediente General de Cofradias (1769-1784). Propuestas para su estudio: Iglesia y Sociedad en el Antiguo Régimen, Las Palmas de Gran Canaria, 1995, pp. 31-40.

El asociacionismo en la iglesia

Hispania Sacra 50 (1998) 
ca. Se trataba de limitar el poder de los gremios y sus trabas a la producción, de aminorar gastos excesivos que redundaban negativamente en las economías familiares más débiles, y de evitar situaciones pontecialmente peligrosas para el orden público. Son, más que orientaciones espirituales, medidas de gobierno y policía.

El estudio en el Consejo de Castilla de algunos casos particulares surgidos en el seno de cofradías madrileñas, proporcionó a los fiscales del Consejo la ocasión de proponer medidas generales y más radicales. El detonante fue la denuncia del obispo de Ciudad Rodrigo en junio de 1768 sobre los abusos de diversas cofradías de su diócesis ${ }^{4}$.

A raíz del dictamen del fiscal Campomanes, decididamente partidario de la reforma de las cofradías ${ }^{5}$, se curso una circular a todos los arzobispos, solicitando información sobre el estado de éstas en sus respectivas archidiócesis. Las respuestas oscilaron entre posturas regalistas e intransigentes como las de los arzobispos de Tarragona y Burgos, y otras más contemporizadoras de los prelados de Granada y Sevilla 6 .

Antes de finalizar ese año se dirigieron otras misivas a los intendentes de la Corona de Castilla y a los corregidores de la Corona de Aragón, encargándoles un censo de hermandades y cofradías de sus distritos respectivos ${ }^{7}$. En Navarra, este censo se encargó al regente, quien comisionó al oidor-decano del Consejo, José Lanciego ${ }^{8}$.

4 La tramitación del Expediente en su conjunto ha sido tratada, con amplitud desigual, en: A. RUMEU DE ARMAS, op. cit., pp. 387-413; F. ABBAD, La confrérie condamnée ou une espontanéité festive confisquée: un'autre aspect de l'Espagne á la fin de l'ancien régime: Mélanges de la Casa de Velázquez, XIII (1977) 361-384; T. A. MANTECón MOVELLÁN, Contrarreforma y religiosidad popular en Cantabria, Santander, 1990, pp. 173-186; M. L. LÓPEZ MUNNOZ, Control estatal de las asociaciones de laicos (1762-1814). Aspectos legales de la extinción de cofradias en España: E. LA PaRRa y J. PRADELLS (eds.), Iglesia, Sociedad y Esiado en España, Francia e ltalia. Siglos XVIll al XX, Alicante, 1991, pp. 341-359.

5 Insistía especialmente cn los gastos: "el demasiado consumo de cera, funciones de pólvora, comilonas, vestidos de los Mayordomos y Hermanos mayores y otras superfluidades ruinosas que unos hacen a emulación de los otros, cstán clamando por una ley suntuaria que reduciendo la devoción de los fieles al espíritu del Evangelio y de la tradición de la Iglesia, redurca estas congregaciones a un número moderado y a la debida observancia" (A.H.N., Consejos, leg. 7090-91).

6 Vid. I. ARIAS DE SAAVEDRA y M. L. LÓPEZ MUÑOZ, Informe de los metropolitanos en el Expediente General de Cofradlas (1769): Publicaciones (Homenaje al profesor Manuel Olmedo Jiménez), 25-27 (1997) 17-54.

7 Vid. I. ARIAS DE SAAVEDRA y M. L. LÓPEZ MUÑOZ, La politica ilustrada ante la religiosidad popular. Intendentes y cofradias en el reinado de Carlos III: P. FERNÁNDEZ ALBADALEJO, J. MARTínEZ Millán y V. PINTO CRESPO (coords.), Política, religión e Inquisición en la España moderna. Homenaje a Joaquín Pérez Villanueva, Madrid, 1996, pp. 85-105.

8 José Matías Lanciego, natural de Viana, ocupó plaza de natural en el Consejo de Navarra desde 1749 hasta su muerte, acaecida en 1779 . Fue en varias ocasiones virrey interino y ocupó también otros 
Dada la especial orografía del reino y la configuración de su hábitat, la confección del informe encontró numerosas dificultades (falta de correos, inclemencias del invierno, aislamiento de los pueblos...), no acabándose hasta 1772. Pese a ello, el informe de Navarra es de los más completos del país, conservándose tanto la información confeccionada a nivel local, ordenada por merindades, como un abultado resumen de la misma que se realizó en el Consejo de Navarra ${ }^{9}$, con información más sintetizada y ajustada a las peticiones del gobierno central. Sobre esta última se ha realizado el presente trabajo, como primera aproximación a las cofradías navarras. Nos referiremos en primer lugar a las de todo el reino, y en segundo lugar particularmente a las de Pamplona.

\section{APROXIMACIÓN A LAS COFRADÍAS DEL REINO DE NAVARRA.}

El Reino de Navarra, incluída Pamplona, tenía, según el informe, 1.166 "organismos colegiados", esto es cofradías, hermandades y gremios. Se mencionan también ciertas fiestas, votos, peregrinaciones y otras asociaciones de laicos, que dado su escaso grado de institucionalización quedan fuera de las cifras globales, aunque se especifican en nota en el Apéndice adjunto.

La distribución geográfica de las cofradías y gremios era la siguiente:

\begin{tabular}{|c|c|}
\hline Merindad de Pamplona & 364 \\
\hline Merindad de Tudela. & 128 \\
\hline Merindad de Olite & 124 \\
\hline 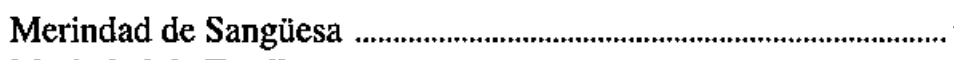 & 298 \\
\hline Merindad de Estella & 252 \\
\hline
\end{tabular}

La presencia de cofradías es realmente importante. Si tomamos como referencia la población del reino consignada en el censo de Floridablanca, encontramos una cofradía por cada 195 habitantes ${ }^{10}$. Dada la dispersión del hábitat

cargos, como el de juez conservador de la renta del tabaco o el de consultor de las Cortes de Pamplona (J. $\mathrm{M}^{\mathrm{a}}$. SESÉ ALEGRE, El Consejo Real de Navarra en el siglo XVIII, Pamplona, 1994, pp. 235-237).

9 El informe del decano José Lanciego se halla fechado ef 1 de marzo de 1772 y consta de 280 fols. (A.H.N., Consejos, leg. 7096).

10 El censo ofrece la cifra de 227.382 habitantes, distribuídos en 830 núcleos de población (Censo Español, executado de orden del Rey, comunicada por el Excmo. Sr. Conde de Floridablanca... Madrid, 1787, ed. facsimil en Madrid, 1987, pliego XXXI). Previamente al infonme dirigido al Consejo de Castilla, se sabía de la existencia de numerosas cofradjas en Navarra, aunque de forma vaga, como lo expresa el obispo Añoa en 1740: "hai muchas Cofradjas, Congregaciones y Hermandades, que no es

El asociacionismo en la iglesia

Hispania Sacra 50 (1998) 
en la geografía navarra, las cofradías se encuentran muy repartidas por más de quinientas entidades de población. Casi todos los núcleos rurales tienen alguna cofradía, pero son naturalmente las ciudades y pueblos más importantes los que concentran mayor número. Muy pocas poblaciones süperan las 20 cofradías: Pamplona 54, Sangüesa 29, Lumbier 27, Tudela 25, Puente la Reina 24, Corella 21, Falces 21 y Tafalla 20. Con diez o más se encuentran otras ocho localidades ${ }^{11}$. Estas cifras son bastante elocuentes sobre la dispersión señalada. Por otra parte, conviene destacar que las cofradías constituyen un elemento de cohesión comarcal, al promover la celebración de romerías, peregrinaciones, etc., que fomentan la sociabilidad dentro de los valles pirenaicos sobre todo, rasgo éste muy peculiar y diferente a lo que ocurre en otras regiones, sobre todo del sur peninsular, donde a veces las cofradías juegan un papel destacado en la rivalidad vecinal.

La inmensa mayoría de estas cofradías están ubicadas en iglesias parroquiales. Más del $85 \%$ tienen por sede la parroquia, siendo éste otro rasgo destacable, pues aunque en el resto del país dominan las sedes parroquiales, no se alcanza un nivel tan elevado. La extensa red parroquial de Navarra -759 parroquias, excluyendo el arciprestazgo de Guipúzcoa, según la relación "ad limina" del obispo de Pamplona de $1594^{12}$ - explica esta realidad. En cuanto a las que tienen su sede en conventos, alcanzan casi el $6 \%$, porcentaje menos significativo que el de otras regiones, como las del sur de España (Murcia más del $10 \%$, diocesis de Granada casi el $15 \%$ ), debido a un número de conventos en la región navarra - no más de cincuenta centros masculinos- relativamente menor. El hábitat rural explica la importancia de las ermitas y basílicas como sedes de las cofradías en Navarra. Este tipo de sede suele albergar a cofradías compuestas de hermanos de distintas localidades, que actúan como referente espiritual de ciertas comarcas (valles, cendeas), etc. Otras sedes - catedral, colegiatas, hospitales- tienen mucha menor significación.

El siguiente cuadro recoge la distribución por sedes de las cofradías y gremios navarros, expresada en términos porcentuales.

\footnotetext{
fácil reducirlas a número, en que se ejercitan varias obras de piedad y misericordia y de particular culto a Dios, a la Virgen Maria y a los Santos" (en J. I. TELLECHEA IDíGORAS, Dos informes episcopales sobre la diócesis de Pamplona. Las visitas ad limina de los obispos D. Juan Grande (I69]) y D. Francisco de Añoa y Busto (I740); Revista Española de Derecho Canónico, 26 (1970) 112).

13 Vera de Bidasoa, Cascante, Cintrućnigo, Peralta, Aoiz, Estella, Lodosa y Viana.

12 J. I. TellecheA IDígoras, La visita ad limina del obispo de Pamplona, Don Bernardo Rojas Sandoval (1594); Revista Española de Derecho Canónico, 21 (1966) 591-617.
} 


\begin{tabular}{||l|c|c|c|c|c|c||}
\hline \multicolumn{7}{|c|}{ SEDES DE LAS COFRADÍAS Y GREMIOS DE NAVARRA } \\
\hline Merindad & PA $^{13}$ & CO & B/E & HO & C/C & Total \\
\hline Pamplona & 87,91 & 6,59 & 4,12 & 0,54 & 0,82 & 99,98 \\
\hline Tudela & 78,12 & 11,71 & 7,81 & & 2,34 & 99,98 \\
\hline Olite & 84,67 & 2,41 & 6,45 & 6,45 & & 99,98 \\
\hline Sangüesa & 87,91 & 8,05 & 3,35 & 0,67 & & 99,98 \\
\hline Estella & 88,88 & 0,39 & 10,71 & & & 99,98 \\
\hline NAVARRA & 86,70 & 5,74 & 6,00 & 1,02 & 0,51 & 99,97 \\
\hline
\end{tabular}

Leyenda: $\mathrm{PA}=$ Parroquias, $\mathrm{CO}=$ Conventos, $\mathrm{B} / \mathrm{E}=$ Basilicas $/$ Ermitas, $\mathrm{HO}=$ Hospitales, $\mathrm{C} / \mathrm{C}=$ Catedral $/$ Colegiatas

En cuanto a las advocaciones, se han considerado las siguientes: sacramentales, de Cristo, marianas, de santos, de ánimas, otras advocaciones y mixtas ${ }^{14}$.

En todo el reino de Navarra hay un claro predominio de las cofradías marianas y de santos, que juntas alcanzan más del $70 \%$ del total. A cierta distan-

\begin{tabular}{|l|c|c|c|c|c|c|c|c|c||}
\hline \multicolumn{8}{||c|}{ ADVOCACIONES DE LAS COFRADIAS Y GREMIOS DE NAVARRA } \\
\hline \hline Merindades & MA & ST & CR & SA & AN & 0T & MX & N.S. & Total \\
\hline Pamplona & 47,80 & 30,49 & 12,08 & 3,02 & 3,84 & 0,82 & & 1,92 & 99,97 \\
\hline Tudela & 21,09 & 43,75 & 21,87 & 2,34 & 3,12 & 0,78 & 3,90 & 3,12 & 99,97 \\
\hline Olite & 21,77 & 47,58 & 15,32 & 2,41 & 2,41 & 0,80 & 2,41 & 7,25 & 99,95 \\
\hline Sangüesa & 34,22 & 33,89 & 14,09 & 6,71 & 1,34 & 4,02 & 2,01 & 3,69 & 99,97 \\
\hline Estella & 36,50 & 31,34 & 25,00 & 2,38 & 1,98 & & 0,39 & 2,38 & 99,97 \\
\hline NAVARRA & 36,19 & 34,81 & 16,80 & 3,68 & 2,57 & 1,45 & 1,28 & 3,17 & 99,95 \\
\hline
\end{tabular}

Leyenda: MA = María, ST = Santos/as, CR $=$ Cristo, $S A=$ Sacramentales, $\mathrm{AN}=$ Ánimas, $\mathrm{OT}=$ Otras, MX = Mixtas, N.S. = No se sabe.

13 La sede parroquial sc ha asignado por defecto a todos los casos donde no se hace mención expresa de la sede de la cofradía, dado que en la mayoria de las localidades no existe otro centro religioso distinto a la parroquia.

14 Se incluyen en este grupo aquéllas que tienen varias advocaciones pertenecientes a más de uno de los grupos referidos. En toda España son muy comunes las mixtas del Santísimo Sacramento y Ánimas del Purgatorio. En Navarra las más frecuentes son las que aglutinan la devoción a María y algún santo.

E] asociacionismo en la iglesia Hispania Sacra 50 (1998) 

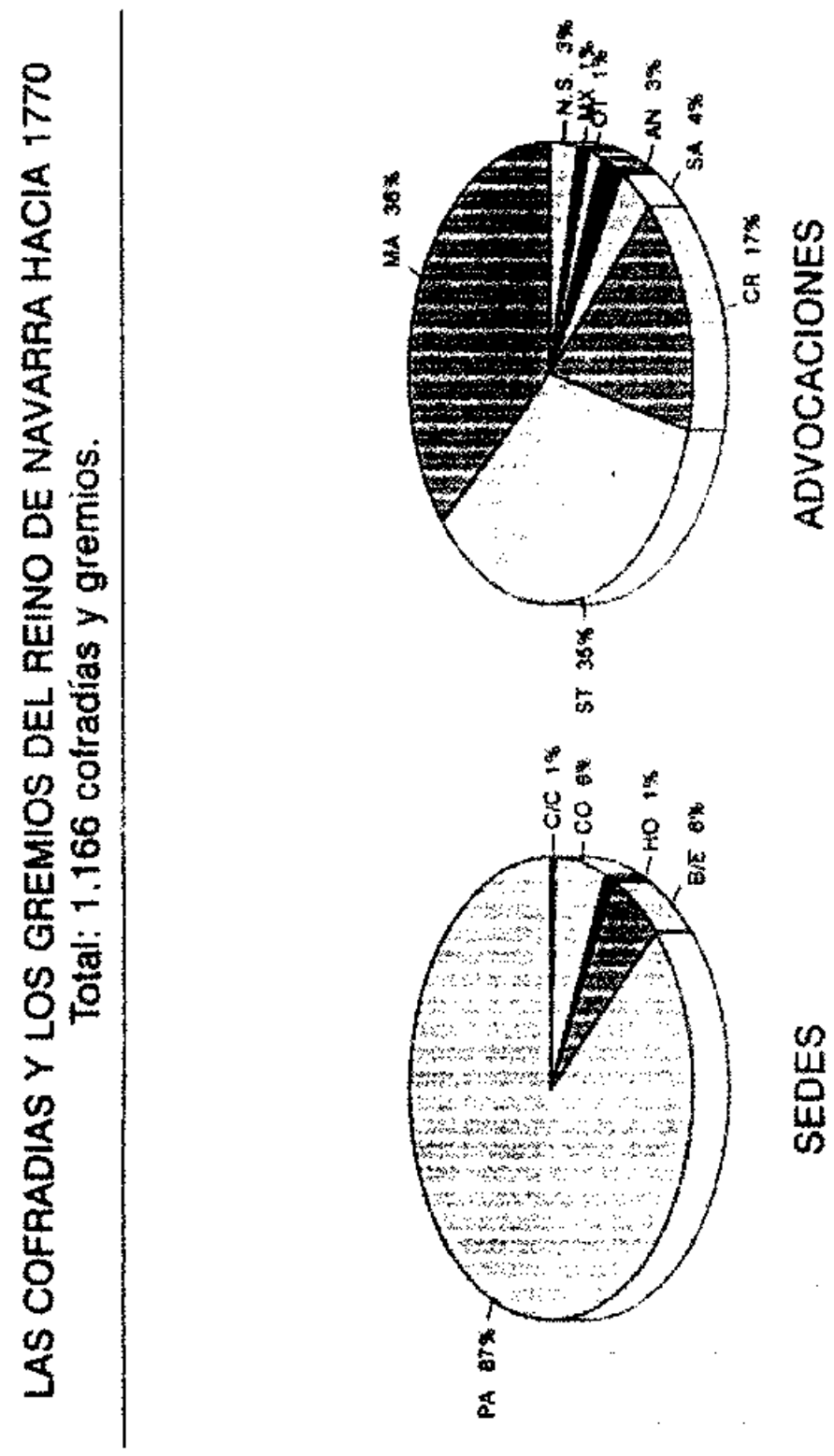

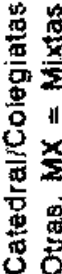

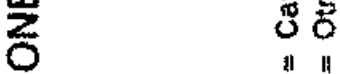

0.

30

sis

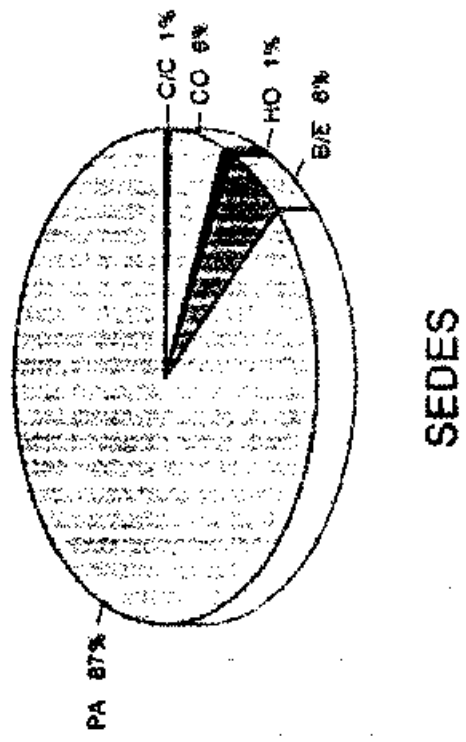

$\frac{\omega}{p}$ 


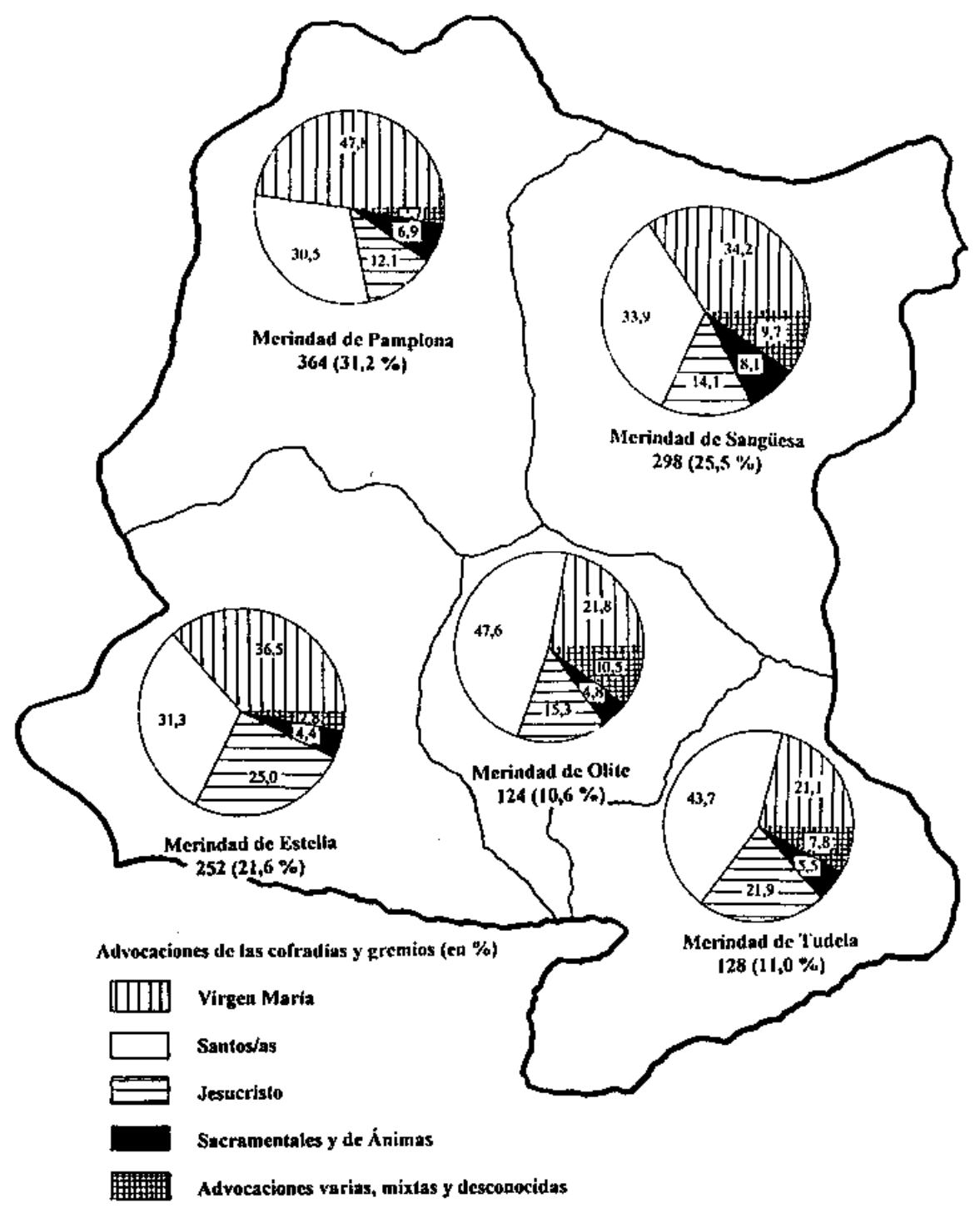

Advocaciones de las cofradías y gremios De las merindades de Navarra en 1772 (sobre las divisiones del mapa de I.B. Nolin de 1762)

El asociacionismo en la iglesia Hispania Sacra 50 (1998) 
cia se encuentran las que tienen advocaciones de Cristo y muy rezagadas las restantes categorías. Como en el caso anterior, el cuadro recoge la distribución tipológica por merindades en términos relativos.

Lo primero que llama la atención es la escasez de hermandades sacramentales, muy extendidas en otras zonas del país, donde suele existir una en cada parroquia. No obstante, la significación de la devoción sacramental es algo mayor de lo que estas cifras indican. Algunas cofradías con advocación de Cristo, en concreto las congregaciones del Sagrado Corazón de Jesús, estaban dedicadas primordialmente al culto eucarístico. En muchos lugares estas congregaciones estuvieron promovidas por el padre Sebastián de Mendiburu ${ }^{15}$ (Ororbia, Goizueta, Burjada...). En los momentos en que se redacta el informe, bastante cercanos a la expulsión de la Compañía, algunas de éstas habían cambiado su titularidad, reconvirtiéndose directamente en sacramentales, por decisión del obispo Juan Lorenzo Irigoyen. Las que conservaban su advocación primitiva tenían agregadas las funciones de la Minerva ${ }^{16}$. También son relativamente escasas las cofradías de Ánimas, que habían alcanzado un notable auge en la España del siglo XVIII. En el apartado de otras advocaciones se incluyen cofradías dedicadas a la Stma. Trinidad -13 en total- y otras como "Oculi mei" o Misericordia.

Descendiendo a advocaciones concretas, sólo 12 aparecen en más de 20 cofradías: Ntra. Sra. del Rosario (312), Vera Cruz o Santa Cruz (122), Stmo. Sacramento (45), S. José (36), Ânimas (33), S. Antón (32), Corazón de Jesús (28), S. Miguel (28), S. Sebastián (25), Ntra. Sra. de Montserrat (22), Santiago (21) y S. Juan (21). Las cinco primeras advocaciones referidas concentran casi la mitad de todas las cofradías navarras, y sólo las del Rosario alcanzan el 27 $\%$ del total. La devoción al Rosario, difundida por los dominicos desde la Edad

I5 Este jesuita (1708-1782), dedicado primero a la ensefranza universitaria en Pamplona, se entregó más tarde a la tarea misional, redactando en lengua vasca un catecismo y varios devocionarios, y difundiendo la devoción al Corazón de Jesús por Guipúzcoa y Navarra.

$15 \mathrm{El}$ ayuntamiento de Burjada el 17 de diciembre de 1771 informaba de ese cambio de naturaleza de la Congregación del Corazón de Jesús: "en su lugar, y el mismo día o segundo dorningo de cada mes, se hace en la misma parroquial la función de la cofradía o congregación del Santísimo Sacramento, con título de Minerva, erijida y fundada en dicha parroquial este presente año de setecientos setenta y uno por el Imo. Sr. D. Juan Lorenzo de Irigoien y Dutari, Obispo de Pamplona, en virtud de un decreto de su Santidad, obtenido por dicho Ilmo. para todo su Obispado en ocho de enero de este presente afto, y presentado y despachado en la Comisaría General de la Cruzada por el Ilmo. Sr. Comisario General D. Manuel Bentura Figueroa, de veinte y ocho de febrero del mismo año; sus funciones son exponer el Santísimo Sacramento los segundos domingos de cada mes a la misa popular y vísperas, después de éstas una hora de exercicio con plática y oración mental, a esto se sigue la procesión con el Santísimo Sacramento, y con el mismo dando la bendición se finaliza; con su dirección corre el párroco, y por no tener esta cofradía fondo alguno ni sus congregantes obligación de contribuir con cosa alguna, se suple la cera en el modo arriba dicho" (A.H.N., Consejos, leg. 7096). 
Media, estaba muy extendida como en el resto del país, a pesar de que en $\mathrm{Na}$ varra sólo existían, según datos del Censo de Floridablanca, cuatro conventos de dominicos. Esta devoción debió tener incluso una significación mayor, dado que otras cofradías marianas incluían el rezo del rosario entre sus actos de culto. También debe destacarse entre las advocaciones marianas la importancia de cofradías patronales, con una clara referencia local (vírgenes de Nieva, Arigorri, Osquia, Legarra, Murugarren, Eunate, Mendigaña, Rocamador, Puy ${ }^{17} . .$. ).

En cuanto a las cofradías de Cristo, además de las ya referidas del Corazón de Jesús, sobresalen las destinadas a los cultos y procesiones de Semana Santa. Las cofradías de la Vera Cruz, como es habitual en toda España, son las dominantes. Promovidas por la orden franciscana, que en Navarra contaba con siete conventos masculinos, gozaban de numerosas indulgencias y privilegios pontificios y un fuerte respaldo popular. Realizaban procesiones de disciplinantes la noche de Jueves Santo. A este grupo son asimilables las que se titulan de la Sangre de Cristo. Otras advocaciones pasionistas son la Cruz a Cuestas, la Columna, la Oración del Huerto, el Descendimiento - con las clásicas ceremonias litúrgico-teatrales-, y el Sepulcro. En algunas localidades se les denominaba "pasos" o "peanas" (Pamplona, Lumbier). Se trataba de unas cofradías poco estructuradas, cuyos gastos se satisfacían entre diez o doce hermanos.

Las cofradías de santos ofrecen gran variedad de advocaciones, a menudo ligadas a las tareas del campo y a determinados oficios artesanales. Entre las primeras destacan las de labradores y ganaderos, cuyas advocaciones más frecuentes son S. Isidro, S. Antón, S. Pascual Bailón, etc. Mayor importancia tuvieron las cofradías gremiales y profesionales, fenómeno netamente urbano, muy destacable en Pamplona y Estella, y en menor medida en otras ciudades del reino. En Pamplona se contaban hasta 32 entre gremios y cofradías ligadas a oficios; en Estella eran $17^{18}$. Por oficios, destacan las cofradías y gremios de zapateros, con los santos Crispín y Crispiniano como patronos; de sastres, con advocaciones muy variadas; de albañiles y carpinteros, con S. José como patrono, cuya devoción fue muy impulsada por la jerarquía eclesiástica durante el siglo XVIII, dentro del esfuerzo por potenciar una religiosidad más humanizada y familiar; de tejedores, cordeleros-alpargateros, pelaires, etc. Un $10 \%$

17 Ésta, por ejemplo, constituía un referente espiritual en la merindad de Estella. Administraba su basílica en esa ciudad la "cofradía de los sesenta" (vid. por extenso en J. ARRAIZA, La Virgen del Puy en Estella y su comarca; Principe de Viana, 51, 190 (1990) 599-617).

18 Dentro de csta cifra, los catorce gremios de Estella se har computado en la estadística general sólo como cinco, número de barrios en que se agrupaban, dado que las cofradías del mismo barrio organizaban sus fiestas de forma unitaria, celebrando corridas de toros y novilladas. Sobre tales tradiciones, vid. J. M. LACARRA, Las corridas de toros en Estella: Príncipe de Viana, 3, 8 (1942) 316-319.

El asociacionismo en la iglesia

Hispania Sacra 50 (1998) 
de todas las corporaciones consignadas en el informe presentan alguna adscripción laboral o profesional.

Los santos oriundos de Navarra gozaban de cierta preferencia, así ocurre con S. Francisco Javier, que se veneraba en la basílica de su localidad natal. Aunque sólo se reseñan diez cofradías con esta advocación, se advierte en las Cortes de Navarra una intención clara de potenciarlas ${ }^{19}$. También es muy característica en la zona la advocación de Santiago, sobre todo en el itinerario del camino de Santiago, especialmente en pueblos con hospitales de peregrinos ${ }^{20}$. Algunas de ellas exigían a los vecinos para su ingreso haber realizado la peregrinación a Compostela (Miranda, Larraga, Ujué).

Un caso particular, no propiamente gremial, que se ha incluído en este apartado, lo constituyen las hermandades de sacerdotes y eclesiásticos. Se contabilizan alrededor de la veintena, con advocaciones diversas, si bien dominan las de S. Pedro y Purísima Concepción. A veces agrupaban sólo a los clérigos naturales de la localidad (Pamplona, Sangüesa), pero lo normal es que incluyeran a todos los residentes en el lugar, asegurándoles un entierro acorde con su condición y sufragios por sus almas.

Del número y antigüedad de las cofradías y gremios se desprende una larga tradición asociativa en la geografía navarra.

Muchas de estas asociaciones consignan varios siglos de existencia al hablar de su fundación ${ }^{21}$. Es un rasgo destacable en el conjunto del país.

En general las cofradías navarras, con excepción de las gremiales, eran de carácter abierto, es decir, no imponían ningún requisito excluyente para la admisión. Una cofradía de tipo medio no tenía más allá de 50 hermanos de ambos sexos. La realidad geográfica del Reino se imponía también en este

19 Las Cortes de Pamplona de 1621 "acordaron que se erija a deboción del beato padre Francisco Jabier, que (h)a de ser patrón del Reyno, una cofradía de cavalleros o hijosdalgo, en que entren los que tubiercn ambas las dichas calidades o qualesquiera d'ellas, entendiéndose que los hijosdalgo sean como se entiende cn este Reyno, con la calidad de limpięa, y que sea patrón de csta cofradía el Reyno y su Diputación" (Actas de las Cortes de Navarra (1530-1829), Pamplona, 1993, vol. II, p. 85). Fue declarado palrón del reino en 1622, decretando la celebración de su fiesta con solemnidad (J. SALCEDO IZU, La Diputación del Reino de Navarra, Pamplona, 1969, vol. I, p. 214).

20 Los hospitales jatonaban las dos rutas navaras (puerto de Aspe y paso de Roncesvalles res pectivamente, que se unían en Puente la Reina). Ś́lo Pamplona llegó a tener hasta diez hospitales de peregrinos (M. NÚṄEZ DE CEPEDA ORTEGA, La Beneficencia en Navarra a través de los siglos, Pamplona, 1940, pp. 22-41). Vid. la obra más reciente sobre el tema de L. VÁZQUEZ DE PARGA, J. M. LACARRA y J. URÍA RIU, Las peregrinaciones a Santiago de Compostela, Pamplona, 1992, 3 vols.

21 Las cofradias navarras juegan un papel muy destacado, si se admite la tesis de Rumeu de la influencia francesa en el origen de las cofradías españolas. Como pieza clave en ese proceso llega a definir a la Cofradía de Santa Cristina de Tudela, que se remonta al siglo XII (A. RUMEU DE ARMAS, op. cit., pp. 34-37). 
rasgo. Naturalmente, en las principales ciudades algunas sobrepasaban largamente esta cifra ${ }^{22}$.

La mayor parte de estas cofradías gozaban de aprobación eclesiástica, casi siempre del ordinario diocesano, pero no faltaba un grupo significativo que gozaba de privilegios pontificios. Algunas, especialmente del Rosario o ubicadas en conventos, sólo contaban con la autorización del superior de la orden. En cuanto a las aprobadas por la autoridad civil — gremios en su mayoría-, habían obtenido su licencia del Consejo de Navarra, en nombre del rey ${ }^{23}$, y en menor medida de los ayuntamientos.

El informe del decano alude a estas aprobaciones en 898 casos (el $77 \%$ de las cofradías navarras). El siguiente cuadro muestra la distribución de esos datos, en términos porcentuales ${ }^{24}$ :

\begin{tabular}{||l|c|c|c|c|c|c|c|c|c||}
\hline \multicolumn{10}{||c|}{ APROBACION DE LAS COFRADÍAS Y GREMIOS DE NAVARRA } \\
\hline \hline Merindades & PO & OB & S.o. & RE & AM & AY & S.A. & N.S. & Total \\
\hline Pamplona & 10,35 & 73,21 & 0,71 & 8,21 & 1,42 & 0,71 & 5,00 & 0,35 & 99,96 \\
\hline Tudela & 6,79 & 49,51 & 1,94 & 13,59 & & 0,97 & 13,59 & 13,59 & 99,98 \\
\hline Olite & 0,85 & 71,79 & 0,85 & 5,12 & & 2,56 & 2,56 & 16,20 & 99,93 \\
\hline Sangüesa & 2,78 & 66,93 & 0,39 & 3,18 & 0,39 & 0,79 & 14,74 & 10,75 & 99,95 \\
\hline Estella & 7,48 & 79,59 & 4,08 & 1,36 & & & 3,40 & 4,08 & 99,99 \\
\hline NAVARRA & 6,12 & 69,59 & 1,33 & 5,90 & 0,55 & 0,89 & 8,12 & 7,46 & 99,96 \\
\hline
\end{tabular}

Leyenda: PO = Pontificia, OB = Obispo, S.O. - Superior de orden religiosa, RE = Real, AM = Ambas (eclesiástica y real), AY = Ayuntamiento, S.A. = Sin aprobación, N.S. = No se sabe.

22 Así ocurría en algunas de Pamplona y de otras localidades. La de San Salvador de Puente la Reina llegó a contar con 440 hermanos en 1729 (vid. en A. DiEZ, Cofradia de San Salvador de Puente la Reina: I Congreso General de Historia de Navarra, Pamplona, 1988, vol, 4, pp. 81-84).

23 Para las cofradías, la aprobación real se consideraba una merced, como se desprende de la aprobación pedida y obtenida por la cofradía de S. Dionis de Tudela en las Cortes de 1611: "porque otras conffradías semejantes de esta, en los reynos de Castilla y otras partes, están devajo la protecçión de Su Magestad o algunos grandes prínçipes, a Vuestra Señoría Illustrísima supplican la recivan devaxo de protecçión y la haga merced de faboreçerla y ampararla, danđola liçençia y facultad para que de aquí adelante se pueda nombrar e intitular horrándole con este título, pues, amás de ser muy grande servicio de Dios, los dichos prior, presidentes y confrades la tendrán a muy grande merced" (Actas de las Cortes... op. cit., vol. Il, p. 34).

24 Los distintos tipos de aprobación no son excluyentes. A la hora de distribuir los datos, hemos consignado siempre la aprobación de rango superior, así la aprobación pontificia se ha preferido a la del obispo, y la de éste a la del superior de una orden religiosa; asimismo la del Consejo de Navarra ha primado sobre la del ayuntamiento. Un ejemplo, la cofradía del Rosario de Oiz se ha incluído entre las pontificias, pero gozaba tambien de las licencias del obispo y del superior de la orden dominicana.

El asociacionismo en la iglesia

Hispania Sacra 50 (1998) 
El momento de aprobación no siempre coincide con el de fundación de la cofradía; a menudo hay un desfase entre ambas fechas, que puede ser incluso de bastantes años. Muchas cofradías navarras son de origen medieval, cuando la exigencia de aprobación por alguna autoridad era menor. El estado modemo $y$, sobre todo, el concilio de Trento afirmaron esta exigencia. Es, por tanto, muy significativa la oleada de aprobaciones eclesiásticas de cofradías ya existentes, en el último tercio del siglo XVI. En la primera mitad del siglo XVIII se observa una nueva oleada, en la que sin duda fue decisiva la actuación de algunos prelados (Camargo y Angulo, Murillo Velarde). La aprobación recaía sobre las reglas o estatutos, documento fundamental de cada cofradía ${ }^{25}$.

Por lo general, se gobernaban por un hermano elegido por uno o dos años, el prior, denominación peculiar de Navarra, cargada de connotaciones eclesiásticas y paternalistas. Este cargo no se limitaba a presidir los actos corporativos, sino que debía velar por la concordia entre los hermanos ${ }^{26}$, lo que lo adornaba de cierta moralidad y ejemplaridad. El prior era auxiliado por un número variable de mayordomos o mayorales, con funciones subalternas, principalmente de captación de fondos.

La situación económica de las cofradías navarras se sitúa por debajo de la media nacional. Gastaban al año un total de 227.027 reales $^{27}$, lo que supone una media de 195 reales por cofradía, menos de la mitad de los 450 reales de media nacional, pero en consonancia con la realidad cofrade del norte del país. Las cofradías se sufragaban con las aportaciones de los cofrades (cuotas) y vecinos (limosnas). Apenas gozaban de propiedades rústicas o urbanas ${ }^{28}$, si bien en las áreas rurales se encuentran a menudo memorias de misas y capella-

25 Son bastantes los estatutos de cofradías navarras conocidos, que se reproducen o resumen en diversos trabajos. A varios de los que se citan en esta comunicación, añadiremos los de $\mathbf{M}^{\mathrm{a}}$. J. LACARRA YANGUAS, Dos Cofradias del siglo XIV en Villafranca (Navarra): Príncipe de Viana, 36, 138-139 (1975) 141-165 y M². S. SILVA VERASTEGUt, Estatutos de Cofradias medievales en el Archivo General de Navarra: Príncipe de Viana, 49, 184 (1988) 215-231.

26 Es una función sitnilar a la ejercida por los priores y mayorales de barrio, elegidos en Pamplona, según lo establecido en las ordenanzas de 1741 y 1749 . En todos los barrios durante la Pascua de Resurrección se celebraban actos de culto a los respectivos patronos, que incluían una ceremonia de reconciliación entre los vecinos: "después de hacer oración, salen a una plazuela próxima y públicamente se reconcilian los mismos de algunas enemistades si las hay" (A.H.N., Consejos, leg. 7096).

27 Informe del contador del Consejo de Castilla, Manuel Navarro, en 30 de octubre de 1775 (A.H.N., Consejos, leg. 7090). Admitimos la cifra con cautela, ya que, ante la escasez de datos, el contador la obtuvo por paralelismo con "la Provincia de Álava, cuyo país se diferencia poco o nada del que se trata".

28 Sirvan de ejemplo los datos de la Cofradía del Rosario de Zubieta en 1763: 36 reales de rentas, 134 de aportaciones de hermanos y 58,5 de limosnas. Los hermanos allegaban casi el $60 \%$ de los ingresos (vid. en J. I. TELLECHEA IDíGORAS, La Cofradia del Rosario de la villa de Zubieta. Nombres y apellidos en la villa (I770-1855): Príncipe de Viana, 31, 118-119 (1970) 271-280).

El asociacionismo en Ja iglesia Hispania Sacra 50 (1998) 
nías que dotaban parte de sus gastos. Los gastos no cubiertos por estos medios eran sufragados principalmente por los cargos directivos o por el conjunto de los cofrades a través de "escotes" o "igualas".

Los actos de culto, objetivo primordial de las cofradías, solían reducirse a la festividad de sus titulares, generalmente con vísperas, función y procesión, celebración de misas en determinados días del año y sufragios por los hermanos difuntos. Este último capítulo era fundamental en la vida de las cofradías y en ocasiones se concretaba con ayuda económica a la familia del difunto para afrontar los gastos del sepelio y de los sufragios. La entrega de una cantidad fija en metálico es un rasgo muy característico de las cofradías navarras, que habían conservado a fines del Antiguo Régimen este elemento de la naturaleza primigenia de las cofradias.

Algunas iban más lejos y asumían el mantenimiento de hospitales y basílicas, e incluso mantenían las fábricas parroquiales como ocurría en Pamplona con las denominadas "obrerías" (S. Cemin y S. Juan). En estas últimas la dependencia y subordinación a la Iglesia aparecen más nítidas. No era raro encontrar arcas de misericordia, dotación de doncellas y otras obras de caridad en las cofradías navarras ${ }^{29}$.

\section{GREMIOS Y COFRADÍAS DE LA CIUDAD DE PAMPLONA.}

Aunque no son propiamente cofradías, los diecinueve barrios pamploneses elegían cada año, por Pascua de Resurrección, un prior y dos o cuatro mayorales, según el número de habitantes, que promovían determinados actos de religiosidad y ocasiones para la sociabilidad, muy similares a las de las cofradías. Se encargaban de "su quietud de día y de noche, evitando desórdenes y turbaciones en las calles y en el interior de las casas, vigilando no se mantengan en ellos - Ios barrios - personas malentretenidas, ociosas y de nota en toda clase de vicios"30.

Estas juntas de barrio celebraban sus actos y funciones en los siguientes templos:

29 La de S. Pedro de Lizarra (Estella), por ejemplo, se dedicaba a "mantener de pan y vestuario a los cofrades pobres, ayudar a rescatar los cautivos de la misma cofradía, dar de comer a trece pobres en su mesa cuando los cofrades comiesen en comunidad, y además dos tibras de pan a cada pobre que concurriese, aunque fuesen 2.000" (J. YANGUAS Y MIRANDA, Diccionario de Antigüedades del Reino de Navarra, Pamplona, 1840, vol. I, p. 227).

30 A.H.N., Consejos, leg. 7096, fol. 1. La población de la capital navara ascendía a 14.066 habitantes en 1787 (en Ma . GeMBero UstÁrroZ, Pamplona en los siglos XVII y XVII: Aspectos económicos y sociales: Príncipe de Viana, 47, 177 (1986) 43-111).

El asociacionismo en la iglesia

Hispania Sacra 50 (1998) 


\section{BARRIO}

Navarrería

Calderería

Tiendas

Cuchillerías

Rúa Mayor

Brullerías

Rúa Chica

Camicerías

Zapaterías

Salinerfas

Juslarrocha

Torredondas

Carpinterías

La Magdalena

Peliejerías

Bolserías

Tecenderías

Tras plaza del Castillo

La Población

\section{TEMPLO}

Basíl. de S. Cecilio

Basíl. de S. Martín

Parroquia

Par. de S. Lorenzo

Convto. de S. Francisco y Par. de S. Lorenzo

Par, de S. Nicolás

Par, de S. Lorenzo y de S. Satumino

Casa-Hospital o Convto. de S. Antón

Par. de S. Lorenzo y Basíl. de S. Cristóbal

Basíl. de la Magdalena y Ermita de S. Cristóbal

Basíl. de Sta. Ana

Basíl. de S. Tirso

Par. de S. Nicolás

Las funciones religiosas solían desarrollarse a lo largo de tres días durante la citada Pascua de Resurrección. Con ligeras variantes, consistían en la celebración de una misa con plática, acto de reconciliación vecinal, elecciones de nuevos cargos acompañadas de "caridades" de pan, vino y queso ofrececidas por los priores saliente y entrante a los vecinos y de comidas más restringidas para aquéllos que habían sido priores o mayorales. Estas agrupaciones de bamios podían tener bienes raíces (casas, censos), pero por lo general no bastaban para los gastos sociales y de culto, que eran sufragados por los priores y por las limosnas recaudadas por los mayorales entre los vecinos. A cargo de estas juntas estaba también el mantenimiento de las lámparas que alumbraban distintas homacinas y altares callejeros, que servían, a su vez, para iluminar el barrio, prestando especial atención a este aspecto fundamental para el mantenimiento del orden y la quietud durante la noche ${ }^{31}$.

31 Los priores habían intentando, infructuosamente, un mayor poder de decisión frente al concejo, apenas cinco años antes de la elaboración de este informe (vid. por extenso en J. ANDRÉsGALLEGO, La demanda de representación en el siglo XVII: el pleito de los barrios de Pamplona (I766): Príncipe de Viana, 49, 183 (1988) 113-126).

El asociacionismo en la iglesia Hispania Sacra 50 (1998) 
En la ciudad de Pamplona, según el informe, había veintiocho cofradías y veintiseis gremios ${ }^{32}$, que se relacionan a continuación, indicando su sede, fecha de fundación y tipo de aprobación:

\section{COFRADIAS}

Oculi Mei

Sta. Catalina

Stos. Cosme y Damián (mé-

dicos, cirujanos, boticarios)

Ntra. Sra. Remedios

S. Crispín (zapateros)

? (labradores)

S. Antonio Padua

Ntra. Sra. Nieva

Stmo. Sacramento

Almas

Sta. Bárbara (mercaderes)

Sta. Bárbara (artilleros)

S. Marcos (cortadores)

Desposorios

S. José

Anguín Obrari

Angel de la Guarda

S. Miguel

S. Lamberto

Montserrat (labradores)

S. Joaquín

Ntra. Sra. Pilar

S. Vicente Ferrer

Ntra. Sta. Camino

Paso del Sepulcro

S. Diego

Paso del Sepulcro

Paso de la Columna

\section{SEDE}

Par. S. Cernin

Par. S. Juan

Cvto. Carmen Calzado

Par. S. Lorenzo

Par. S. Lorenzo

Par. S. Lorenzo

Cvto. S. Francisco

Cvto. Sto. Domingo

Catedral

Hospital General

Hospital General

Cvto. S. Francisco

Par. S. Nicolás

Par. S. Satumino

Cvto. Carmen Calzado

Basílica-Hospital

Cvto. Carmen Calzado

Par. S. Saturnino

Par. S. Lorenzo

Cvto. Merced

Cvto. Carmen Descalzo

Cvto. S. Agustín

Cvto. Sto. Domingo

Par. S. Saturnino

Cvto. S. Agustín

Cvto. S. Francisco

Cvto. S. Francisco

Cvto. Merced
FUNDACIÓN APROBACIÓN

$\begin{array}{cc}1341 & \text { Obispo } \\ 1327 & \text { Papa }\end{array}$

$1493 \quad$ Rey

$\begin{array}{cc} & \text { Obispo } \\ 1317 & \text { Obispo } \\ 1647 & \text { Obispo } \\ 1599 & \text { Obispo } \\ 1599 & \text { Obispo/Rey } \\ 1532 & \text { Papa } \\ 1680 & \text { Obispo } \\ 1716 & \text { Obispo } \\ & \text { Papa } \\ 1629 & \text { Obispo } \\ 1674 & \text { Obispo } \\ 1620 & \text { sin aprobacion } \\ 1590 & \text { Obispo/Rey } \\ 1722 & \text { Obispo } \\ 1679 & \text { Obispo } \\ & \text { Papa } \\ 1685 & \text { Obispo } \\ 1764 & \text { Rey } \\ 1671 & \text { Obispo } \\ 1653 & \end{array}$

sin aprobación

32 Falta aún un estudio sistemático de esta realidad pamplonesa. La obra pionera de Núñez de Cepeda (M. NúN̄EZ DE CEPEDA ORTEGA, Los antiguos gremios y cofradias de Pamplona, Pamplona, 1948), paralela a la ya mencionada que dedica a la beneficencia, está escrita en clave đe eruđición nostálgica. Sin embargo, las referencias a cofradías abundan en artículos y trabajos de historia local, del mundo eclesístico y, sobre todo, de centros religiosos (parroquias, conventos, basílicas), tanto de Pamplona como de todo el reino de Navarra, algunos de los cuales se citan en este trabajo. Gregorio Silanes se propone el estudio de las cofradías de Pamplona, como se desprende de su primera aproximación (G. SILANES SUSAETA, Algunas consideraciones sobre la historia de las cofradias de una ciudad española: Ciencias Humanas y Sociedad, Madrid, 1993, pp. 247-254).

El asociacionismo en la iglesia

Hispania Sacra 50 (1998) 


\begin{tabular}{|c|c|c|c|c|}
\hline GREMIOS & ADVOCACIÓN & SEDE & FUNDACIÓN & APROBACI \\
\hline Cargadores & S. Jorge & Par. S. Saturnino & 1727 & Obispo \\
\hline Latoneros & V. Pilar & Par. S. Nicolás & 1742 & Rey \\
\hline Tundidores & Sta. Lucía & & 1587 & Rey \\
\hline Guanteros & Sta. Bárbara & & 1569 & Obispo/Rey \\
\hline Calceteros & Sta. Lucía & Cvto. Sto. Domingo & 1550 & Rey \\
\hline Herradores & S. Eloy & Cvto. Merced & & Obispo \\
\hline Zapateros & $\begin{array}{l}\text { Stos. Eloy, Cris- } \\
\text { pín y Crispiniano }\end{array}$ & $\begin{array}{l}\text { Par. S. Nicolas y S. } \\
\text { Lorenzo }\end{array}$ & 1430 & Rey \\
\hline Esquiladores & S. Babíl & Par. S. Nicolás & 1725 & Rey \\
\hline Cordeleros & María & Cvto. Merced & 1573 & Rey \\
\hline Cerrajeros & S. Eloy & Cvto. S. Francisco & & Rey \\
\hline Pasteleros & Ascensión & Cvto. Merced & & Ayuntamiento \\
\hline Tejedores & Pur. Concepción & Cvto. S. Francisco & & Rey \\
\hline $\begin{array}{l}\text { Pelaires/tejedores } \\
\text { paño }\end{array}$ & Paso Sta. Cruz & Par. S. Saturnino & & Rey \\
\hline Obrería & S. Cernin & Par. S. Saturnino & & \\
\hline Sastres & Sta. Ana & Cvto. Sto. Domingo & 1526 & Rey \\
\hline Silleros & Sta. Lucía & Cvto. S. Agustín & 1661 & Obispo \\
\hline Estañeros & S. Eloy & Par. S. Nicolas & 1678 & Rey \\
\hline Fajeros Real & & & & \\
\hline Tabla & S. Blas & & 1767 & sin aprobaci \\
\hline$?$ & Sicte Espadas & Cvto. Merced & & \\
\hline Chocolateros & Sto. Cristo & Par. S. Nicolás & 1728 & Rey \\
\hline Cereros & Natividad María & & & Obispo/Re \\
\hline $\begin{array}{l}\text { Albaniles, car- } \\
\text { pinteros, cuberos }\end{array}$ & & & & \\
\hline$y$ tomeros & S. José & Catedral & 1430 & Rey \\
\hline Boteros & Cvto. Merced & & 1611 & Rey \\
\hline Obrería & S. Juan & Par. S. Juan & & \\
\hline Sombrereros & & & 1679 & Rey \\
\hline Plateros & S. Eloy & Par. S. Saturnino & 1582 & Rey \\
\hline
\end{tabular}

Según las relaciones anteriores, en Pamplona predominan las cofradías y gremios con advocaciones de santos (31), seguidas por las marianas (11), de Jesús (6), mientras que las del Santísimo y Ánimas estaban muy escasamente representadas (1 de cada tipo). Se reparten casi por igual entre iglesias parroquiales y conventos de mendicantes; además, dos se ubican en la Catedral y otras dos en sus respectivos hospitales. 


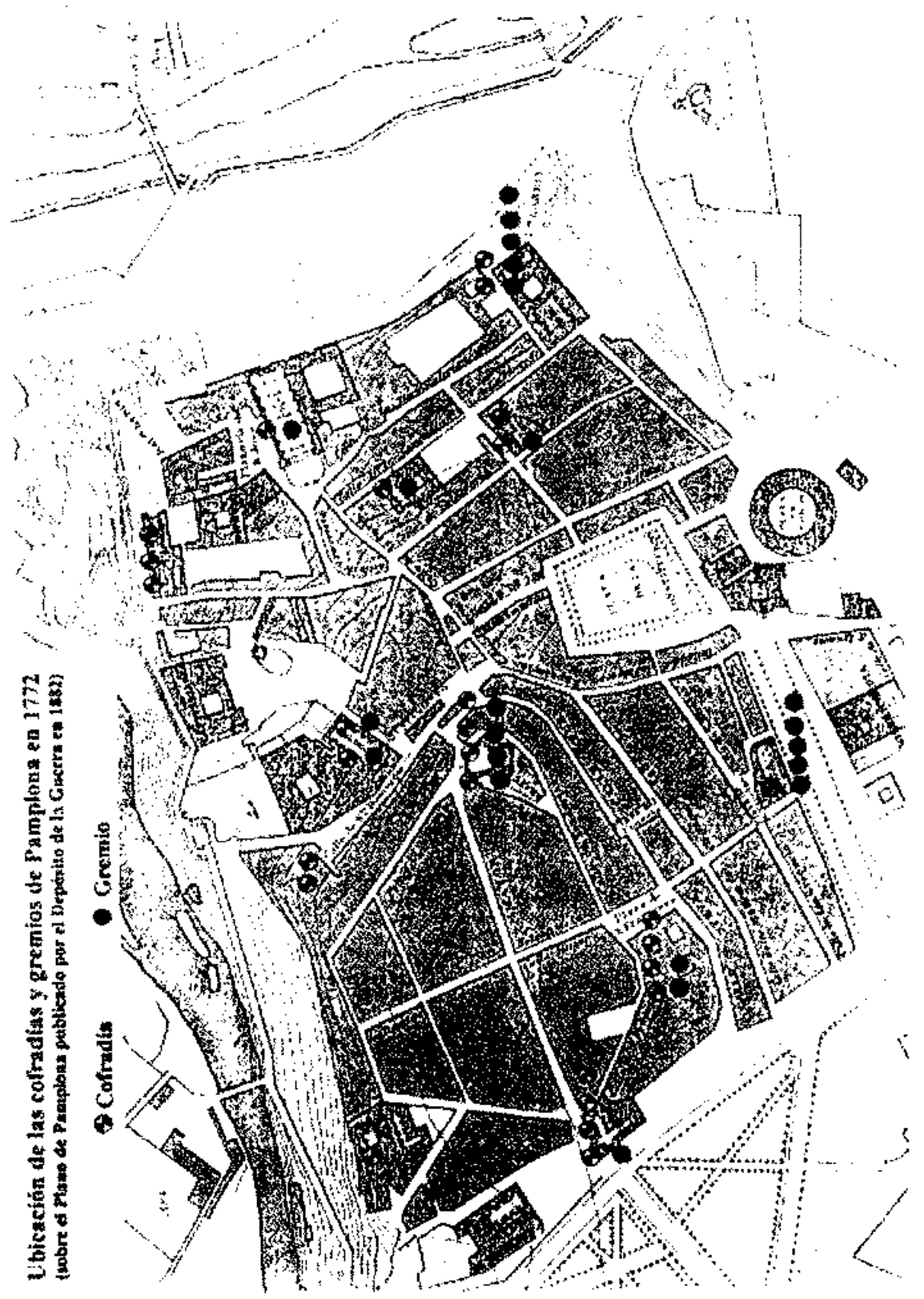

El asociacionismo en la iglesia

Hispania Sacra 50 (1998) 
Cofradías hospitalarias eran la de Anguín Obrari y la del Stmo. Sacramento. La primera mantenía un albergue $e^{33}$ y la segunda, con sede en la capilla de Barbazana en la Catedral, regía un hospital excesivamente corporativo ${ }^{34}$.

Por su particularidad, merece ser mencionada la existencia de dos "obrerías", en las parroquias de San Cernin o S. Satumino y de S. Juan ${ }^{35}$, que se destinaban a su mantenimiento; debieron existir también en las otras dos parroquias. Estaban gobernadas por un obrero mayor y dos obreros menores; el resto de los cofrades u obreros actúaban como "obreros de semana" durante el año. No se conoce su fecha de fundación y aprobación, lo que hace pensar que su origen se remonta a la construcción de los templos. Salvo algún acto de culto, poco hay que destacar de estos "gremios", más preocupados por la celebración de comidas y refrescos ${ }^{36}$ que de la actividad cultual. El obrero mayor de la Obrería de la parroquia de $\mathrm{S}$. Juan tenía voto en la elección de coristas de la misma y se obligaba al mantenimiento de la lámpara del Santísimo.

El número de hermanos era muy variable en las cofradías de Pamplona. Sólo siete consignan este dato en el informe, pero hallar una cifra media parece irrelevante, pues el abanico se extiende desde 40 (S. Miguel) a 580 (S. José). Tan sólo la cofradía de Oculi Mei, con 60 hermanos (20 eclesiásticos y 40 seglares) tiene el carácter de cerrada en cuanto al número, pero en el momento de confeccionarse el informe no alcanzaba la cifra permitida por los estatutos $^{37}$. En cuanto a los gremios, la disparidad también es muy notable, justificada por la propia naturaleza de los oficios; el sector secundario agrupaba en

33 Se destinaba a "recojer por las noches pobres mendigos forasteros, asy hombres como mugeres con la correspondiente... separación, a cuyo fín mantiene en cl día nueve camas en que también dan havitación a un hombre y a una muger con el título de hospitaleros" (A.H.N., Consejos, leg. 7096, fol. 17).

34 "En el hospital de San Martín, propio de esta colradia, da recogimiento a 16 pobres mujeres, prefiriendo las que sean más y hayan estado casadas con sujetos que hubiesen tenido cargo o empleo en la cofradia" (A.H.N., Consejos, leg. 7096, fol. 12). Vid. sobre su financiación, M. NúÑEZ DE CEPEDA, op. cit., pp. J66-167.

35 Ambas feligresías agrupaban, respectivamente, el $28 \%$ y el $34 \%$ de las cofradías de la ciudad, aunque la densidad de tales fundaciones, si se considera la poblacion, era mayor en $\mathbf{S}$. Cernin que en S. Juan, ya que en 1796 la primera agrupaba al $19.65 \%$ de la población y la segunda, la más poblada, al $38,18 \%$. La diferencia población-cofradías era también acusada en la demarcación de S. Nicolás (12 $\%$ de las agrupaciones y $21,63 \%$ de los habitantes en 1796) y más equilibrada en S. Lorenzo (26\% y $20,52 \%$ respectivamente). Vid. datos poblacionales en $\mathrm{M}^{\mathrm{a}}$. GEMBERO USTARROZ, op. cit., p. 47.

36 La Obrería de S. Cemín gastaba al año 480 reales en comidas el día de Todos los Santos y la octava de Ntra. Sra. del Camino, y una colación la noche del Jucves Santo, para lo que pedía limosnas cn Pascua de Resurrección, An̄o Nucvo y Reyes, además de recibir una sustanciosa subvención de la partoquia (A.H.N., Consejos, leg. 7096, fol. 32).

37 También la de $\mathbf{S}$. Miguel fue cerrada (72 hermanos), al menos en su origen, lo que podría explicar el reducido númeto de cofrades que presenta. Vid. J. BALEZTENA, Fundación de la Cofradía de San Miguel en Pamplona. 1674: Príncipe de Viana, 52, 192 (1991) 153-161.

El asociacionismo en la jglesia Hispania Sacra 50 (1998) 
Pamplona en 1787 a la tercera parte de la población. El gremio de albañiles con ochenta miembros ${ }^{38}$, seguido del de pelaires, con veintitrés, son los más numerosos; el de tundidores, por el contrario, agrupa a tan sólo tres personas ${ }^{39}$.

Como en el resto de Navarra, el cargo de prior es la máxima autoridad de la cofradía, auxiliado por diputados y mayordomos, que en ocasiones reciben el nombre de mayorales ${ }^{40}$. En las cofradías hospitalarias se añaden también los oficios de capellanes y enfermeros, y en cuanto a los gremios, además del prior son esenciales dos veedores por oficio y los contadores.

En el terreno económico, según el informe, sólo siete cofradías y cuatro gremios tenían bienes raíces. La cofradía más rica de Pamplona era la de Sta. Catalina, de la parroquia de S. Juan, que tenía casas, una huerta y censos que porducían anualmente 1.583 reales. Otra cofradía bien dotada era la de cortadores de S. Marcos, que poseía tres capellanías con una renta de 72 ducados anuales. La mayor parte de laș cofradías se costeaban, no obstante, con las cuotas de sus socios y las limosnas de los fieles. Las cuotas de entrada eran muy variadas, aunque la mayoría eran cantidades modestas (6-8 reales), no faltaban cuotas tan elevadas que convertían an la cofradía en un reducto muy selecto. La de cortadores de S. Marcos exigía diez ducados en el ingreso del cofrade y la de Oculi Mei, que tenía establecido un numerus clausus, hacía pagar 88 reales a los varones y la mitad a las mujeres a la hora de ingresar.

En los gremios, los derechos de examen constituían la cuota de entrada y eran a menudo más elevadas: 100 reales los latoneros, 10 ducados los tundidores y pelaires..., pero no faltaban cantidades más pequeñas en oficios modestos (chocolateros, 5 reales).

Por lo que se refiere a la cuota ordinaria, solía estar en tomo a 3 ó 4 reales al año. Algunas cofradías tenían cuotas extraordinarias que se pagaban a la muerte de los hermanos: Stos. Cosme y Damián 99 reales, S. Antonio 87 reales, etc...

En las cofradías pamplonesas estaba muy extendida la práctica de dar a la familia del hermano fallecido una cantidad en metálico para sufragar los gastos del entierro. Con frecuencia, esta cantidad se añadía a sufragios específicos que la cofradía ofrecía por su alma. En veintiseis casos, entre cofradías y gremios, hemos encontrado reseñada la cantidad que se daba a los herederos. La

38 Englobaba también a los carpinteros y a otros oficios. Vid. J. L. MULINS MUGUETA, Artistas competentes en el trabajo de la madera, examinados por la Hermandad de San José y Santo Tomás de Pamplona entre 1587 y 1650: I Congreso de Historia de Navarra, Pamplona, 1988, vol. 6, pp. 363-380.

39 Entre los oficios con hermandad propia destacan por su número en el Censo de Godoy (1797) los sastres (210), los albañiles y carpinteros (173, incluidos los peones), los zapateros (1.25, incluidos los alpargateros), los pelaires (101) y los chocolateros (70). Vid. datos en $\mathbf{M}^{\mathrm{z}}$. GEMBERO USTARROZ, op. cit., pp. 109-111.

40 Vid. la caracterizacion de esos cargos en G. SILANES SUSAETA, op. cit., pp. 251-252.

El asociacionismo en la iglesia

Hispania Sacra 50 (1998) 
cifra más alta la ostentan los cortadores de $S$. Marcos con 30 ducados (330 r.), seguidos de los plateros (211 r.), sastres (143 r.), albañiles (116 r.), calceteros (110 r.), etc... En la escala más baja estaban los cordeleros (12 r.), los cofrades de S. Vicente Ferrer (33 r.), los del Paso de la Columna (35 r.) o los de S. Diego $(50 \mathrm{r}$ ). Estas cifras reflejan la distinta importancia económica de los oficios, así como el grado de ostentación que estas corporaciones tenían, en actos de la importancia social de los entierros.

El fin explícito de las cofradías es promover el culto. Las cofradías de Pamplona celebraban todas actos de culto en número muy variado, desde las que sólo celebran la festividad del patrón (víspera, misa, sermón y procesión), a aquéllas que distribuyen numerosos actos de culto y sufragios de difuntos a lo largo del año. Las misas cantadas y rezadas son el culto más frecuente, pero encontramos también rogativas, viáticos, romerías, etc. La mayor parte asistía a las dos procesiones generales que se celebraban en la ciudad, la del Corpus Christi y la del santo patrón S. Fermín.

Además de sus fines explícitos, las cofradías cumplían una importante función como promotoras de sociabilidad. Conectadas a las prácticas religiosas, realizaban importantes actividades lúdicas, las más frecuentes de las cuales, como en todo el país, eran los refrescos y comidas. Conocida la oposición de las autoridades ilustradas hacia estas prácticas, que pretendían erradicar, a lo largo del informe se advierte un interés por eludir la descripción de estos festejos, que consideramos parte esencial de sus actividades. Se trataba en algunos casos de simples "caridades" (entrega de un panecillo el día de las elecciones en la hermandad de S. Diego) o de pan, vino y queso en la mayoría de los casos; otras veces, el "regalo" de manjares era más sustancioso y delicado"1. Lo más frecuente eran las comidas de los oficiales.

En algunos casos se encuentran gastos destinados a cohetes (S. Antonio de Padua), hogueras (Angel de la Guarda) y, por su especial significación, a corridas de toros (Ntra. Sra. de Montserrat) ${ }^{42}$. En este aspecto, tiene un protagonismo especial la cofradía de cortadores de $\mathrm{S}$. Marcos, que celebraba función en honor de S. Fermín - que se había convertido en titular de la cofradía en lugar de S. Marcos-y procesión el Jueves Santo. Coincidiendo con la festivi-

41 En la hermandad de Oculi Mei se entregaba a cada hermano "un par de perdices, un capón, un frasco de vino y dos naranjas; y a las mujeres un par de perdices, dos naranjas y una porcion de manjar blanco", que se costeaban con los fondos de un patronato creado cn el siglo XIV (A.H.N., Consejos, leg. 7096).

42 Sobre estos elementos de las fiestas pamplonesas, puede verse J. RAMOS, Elementos que com. ponen la fiesta en Pamplona en el siglo XVII: I Congreso de Historia de Navarra de los siglos XVIII, XIX y XX. Pamplona, 1986, vol. II, pp. 401-415. 
dad de S. Fermín, destinaba fondos a "correr los bueyes", origen de los encieros actuales. Obtenía ingresos de la venta de carne durante la Cuaresma.

\section{DICTAMEN DEL CONSEJO DE NAVARRA.}

A la luz de toda la información llegada al Consejo de Navarra -en ocasiones muy crítica con las cofradías ${ }^{43}$ - , su decano, José Lanciego, realizó un dictamen sobre el destino de las cofradías y gremios, según las intrucciones del Consejo de Castilla. Vistos en su conjunto los más de diez folios que comprende, se desprende una actitud de benevolencia y tolerancia hacia las cofradías $^{44}$. Pero consciente de la necesidad de reformar ciertos excesos, pasa revista a distintos aspectos de la realidad cofrade.

Lanciego se muestra partidario de mantener los actos de culto de las juntas de barrio de la ciudad de Pamplona, sobre todo las reconciliaciones que tenían lugar por Pascua, como medios para mantener la paz social. En cuanto a las comidas y refrescos, apunta que no son muy gravosas para los priores y que además están toleradas por la costumbre, a pesar de estar prohibidas por las leyes.

Respecto a las cofradías propiamente dichas, su valoración es positiva. No encuentra abusos destacables en gastos ni rentas, ni ostentación excesiva en el culto, mantenido en los límites de la decencia. Las comidas de las cofradías debían suprimirse, sin que ello significara la abolición de las corporaciones. No ha de temerse que la supresión de estos festejos conlleve la desaparición de la cofradía ${ }^{45}$. Por el contrario, valora muy positivamente la actividad benéficoasistencial de las cofradías en el momento de la muerte del cofrade ${ }^{46}$. Sin sus ayudas, algunos vecinos se enterrarían de forma miserable.

43 Por ejemplo, la del regiđor de Falces Jerónimo Maya de Arrechea en 1771, que entre otras cosas dice de los mayordomos que "de tres partes, las dos de éstos son pobres, y por quedar en su comida con algún lucimiento quedan empeñados para todo el año y quántas veces (iqué lástima!) los demás cofrades buscan el dinero para pagar la cornida y su pobre familia sin pan en casa" (A.H.N., Consejos, leg. 7096).

44 "Atendido el intrínseco y primario objeto de su establecimiento, son unos cuerpos piadosos e inocentes dirijidos al culto y al exerzizio de actos de piedad, por lo que considerados en sí, no hallo motibo para su abolición" (A.H.N., Consejos, leg. 7096).

45 "Si en algunos pueblos por este motivo cesaren las cofradías, importará poco que se deshagan unos cuerpos, que su conservación depende de un motivo tan grosero y no de la devoción" (A.H.N., Consejos, leg. 7096).

46 "Tienen los pobres este socorro en tiempo en que suelen estar las casas y familias más necesitadas con los precisos gastos de una enfermedad, en que además han estado privadas de la utilidad y empleo de sus oficios" (A.H.N., Consejos, leg. 7096).

El asociacionismo en fa iglesia

Hispania Sacra 50 (1998) 
En relación con las cofradías gremiales, reconoce que se hallaban prohibidas por las leyes desde el siglo XVI - Cortes de Sangüesa de 1561-, con excepción de la de S. Cosme y S. Damián de médicos, cirujanos y boticarios de Pamplona, por sentencia del Consejo de Navarra, "porque los que entrasen en dichos oficios sean bien examinados y se tengan consultas para las cosas que tocaren a la salud y porque en ella no puede haver monipodios". Sin embargo, señala cómo son toleradas por la costumbre y realizan sus actividades a la luz pública con el consentimiento tácito de las autoridades. Cualquier decisión sobre su continuidad la relega al Consejo de Navarra.

El número de cofradías es ciertamente elevado, pero se justifica por la dispersión de pueblos y lugares, a menudo con una sola cofradía ${ }^{47}$. En las localidades más importantes podría justificarse la reducciôn, tras un estudio pormenorizado del mismo Consejo de Navarra, auxiliado por las autoridades locales.

Su voz, por último, se hace más crítica al hablar de las romerías, que considera ocasión de todo tipo de peligros. Sabedor de que las cofradías justificaban las comidas en las romerías en función de la larga distancia recorrida, recomienda que no se permitan funciones de culto en ermitas muy distantes de los pueblos ${ }^{48}$.

\section{CONCLUSIONES.}

En el conjunto de los territorios peninsulares, Navarra se caracteriza por una notable concentración de cofradías, mayor de lo que cabía esperar en atención a su población. Casi el $5 \%$ del total de las cofradías españolas estaban ubicadas en territorio navarro. La importancia económica de estas asociaciones, sin embargo, era más modesta, al situarse por debajo de la media nacional en cuanto a gastos; sólo un $2 \%$ de los gastos de las cofradías españolas recogidas en el Expediente, corresponde a Navarra, aunque, como se indicó, este dato es poco exhaustivo.

La tipología de estas cofradías presenta, como en el resto de España, un dominio de las de Cristo, María y los santos, advirtiéndose la peculiaridad de

47 "Me parece que en los pueblos pequeños, de que abunda este Reyno, no hay exceso de cofradias, pues sobre que muchos no la tienen, en los otros es por lo común una, dos o tres, y de tan corta entidad que sus cofrades, con una ligerísima contribución, pueden llevar su cofradia por ser sus gastos de corta entidad" (A.H.N., Consejos, leg. 7096).

48 "Me parecía arreglado que además de la prohivición de las comidas, se mandase por punto general que en las basilicas situadas fuera de los pueblos, no se hiciesen estas funciones, sino dentro de la población, para que acabada la función, puedan los concurrentes retirarse a sus casas" (A.H.N., Consejos, leg. 7096). Algunas cofradias tenían sanción oficial para celebrar comidas, como ocurría en Tudela, autorizadas, según uso y costumbre, por las Cortes de 1596 (Actas de las Cortes... op. cit., vol. I, p. 589). 
una menor importancia de las cofradías sacramentales. Por la especial configuración del hábitat navarro, la mayoría de ellas se encuentran en el ámbito rural y ubicadas en iglesias parroquiales. El número de las establecidas en conventos es relativamente menor, pero en consonancia con la implantación que las ordenes mendicantes tenían en este territorio a fines del siglo XVIII.

La cofradía rural navarra, la más extendida, constituía un medio de identificación comarcal, como muestran las romerías y peregrinaciones populares a basílicas en los días de sus festividades, convertidas en importantes vehículos de sociabilidad.

Pamplona ofrece un buen ejemplo de cofradías y gremios de carácter urbano, con un mayor número de asociados y un nivel de gastos y rentas más importante. Estas corporaciones participaban activamente en las manifestaciones lúdico-religiosas de la ciudad y contaban con un gran arraigo y respaldo social, como muestra la posición de las autoridades locales ante la Administración que pretendía su reforma.

El informe del decano del Consejo de Navarra constituye un buen ejemplo de la actitud conservadora de las autoridades locales, que aunque proclaman la colaboración con las directrices reformistas gubemamentales, en realidad, escudándose en la tradición y en el respaldo popular, son reacias a suprimir de raíz las causas de los excesos y en todo caso consideraban que la corrección de los más llamativos debía hacerse a través de las autoridades forales. Una muestra más de cómo ciertos particularismos esconden actitudes conservadoras en el período ilustrado, que se harían dramáticamente patentes en el siglo XIX.

La actitud reformista del equipo ilustrado en relación con la religiosidad popular, particularmente las cofradías, es bien conocida. ¿Cómo se tradujo en la realidad? En el estado actual de los conocimientos, se puede afirmar que el alcance de la reforma fue muy limitado. El Expediente General que sirve a los historiadores como instantánea de la realidad cofrade en un momento concreto, no sirvió entonces para suprimir aquéllas que, según los informes, no se ajustaban a la religiosidad "janseninzante" que se quería imponer, ni siquiera para erradicar aquéllas que se encontraban en clara situación de ilegalidad (cofradías gremiales, cofradías carentes de aprobación...). Poco después, los agobios hacendísticos del gobiemo de Carlos IV les asestaron un duro golpe al desamortizar sus bienes, lo que afectó muy negativamente a las cofradías hospitalarias, que solían ser las mejor dotadas. De todos modos, las cofradías se resistieron, más aún en aquellas zonas donde los cambios económicos y las innovaciones sociales tardarían mucho en llegar. Por ello, es fácil aventurar que Navarra conservó en buena parte y durante mucho tiempo la estructura de cofradías heredada del Antiguo Régimen. 


\section{APÉNDICE}

\section{DISTRIBUCIÓN GEOGRÁFICA DE LAS COFRADÍAS Y GREMIOS DE NAVARRA}

\begin{tabular}{|c|c|c|c|c|c|c|c|}
\hline REINO DE & & COMUN DE VALLE & & SARASA & 2 & NAVAZ & 2 \\
\hline NAVARRA & 1.166 & MURUZABAL & 3 & ZUASTI & 1 & ARISTAIN & \\
\hline & & OBANOS & 3 & IZA, ARIZ, OCHOVI Y & & & \\
\hline MERINDAD DE & & PUENTE LA REINA & & ERIZE & 1 & VALLE DE OLLO & \\
\hline PAMPLONA & 364 & & & ATONDO & 1 & BEASOAIN & \\
\hline & & CENDEA DE CIZUR & & ANOZ, SALDISE Y & & EGUILLOR & \\
\hline PAMPLONA & 54 & CIZUR MAYOR & 2 & LETES & 1 & OLLO, SENOSIAIN, & \\
\hline & & GAZOLAZ & 1 & & & ARTETA, ULZU- & \\
\hline VALLE DE EZC & R. & ASTRAIN & 2 & CENDEA DE AN. & & RRUNE II ZARBE & 1 \\
\hline BARTE & & MURU & 1 & SOAIN & & & \\
\hline AZOZ & 1 & UNDIANO & 1 & AÑEZCAR Y OTEIZA & & VALLE DE ERGO- & \\
\hline ANOZ & 1 & SAGÜES & 1 & ELCARTE & 1 & YENA & \\
\hline MAQUIRRIAN, A & RCE & BARAÑAIN & 1 & LARRAGUETA, LOZA & & UNANOA & \\
\hline Y SORAUSON & 1 & & & BALLARIAIN 6, BE & & TORRANO & 1 \\
\hline ZILDOZ & 2 & CENDEA DE OLZA & & RRIOSUSO, Al- & & LIZARRAGA & 3 \\
\hline ORICAIN & 2 & GUENDULAIN & 2 & ZOAIN, BERRIO- & & & \\
\hline EUSA & 2 & & & ZAR, ARTICA Y & & VALLE DE BURUNDA & \\
\hline BASILICA TRINI & DAD2 & VALLE DE ECHAU & & ANSOAIN & 1 & BACAICOA & 3 \\
\hline & & ARAZURI & $\mathbf{1}$ & ANSOAIN & 1 & ITURMENDI & 3 \\
\hline CENDEA DE GA & LAR & ORORBIA & 3 & BERRIOZAR & 1 & ALSASUA & \\
\hline ESPARZA & 2 & IZQUE & 1 & AIZOAIN & 1 & CIORDIA & 2 \\
\hline ESQUIROZ & 1 & ASIAIN & 2 & BERRIOSUSO & 2 & OLAZAGUTIA & 2 \\
\hline OLAZ & 1 & LIZASOAIN & 1 & LARRAGUETA & 1 & URDIAIN & 3 \\
\hline SALINAS & 1 & ARRAIZA & 1 & & & & \\
\hline SUBIZA & 2 & BELASSQUOAIN & 1 & VALLE DE GULINA & & VALLE DE IBARGO- & \\
\hline & & ECHAURI & 1 & GULINA & 1 & YARRA & \\
\hline VALLE DE ILZA & RBE & & & & & DONAAMARIA & 1 \\
\hline AÑORBE & 4 & CENDEA DE IZA & & VALLE DE JUSLA- & & GAZTELU & 1 \\
\hline $\mathrm{OLCOZ}$ & 1 & OLZA & 1 & PENA & & & \\
\hline BIURRUN' & 1 & IZU & 1 & MARCALAIN & 2 & VALLE DE SANTES- & \\
\hline UCAR & 1 & ARTAZCOZ & 2 & BEOMBURU & 1 & TEBAN DE LERIN & \\
\hline ENERIZ & 3 & IBERO & $\mathbf{I}$ & BELZUNCE & 2 & URROZ & 1 \\
\hline TIRAPU & 1 & ORCOYEN & 1 & LARRAIOZ & 2 & OIZ & $\mathbf{1}$ \\
\hline LEGARDA & 1 & ALDAVA & 2 & OSINAGA & 2 & ELGORRIAGA & 1 \\
\hline ADlOS2 & 1 & ALDAZ ECHAVA- & & NUIN & 2 & ITUREN & 1 \\
\hline UTERGA & 3 & COIZ & 1 & UNZU & 1 & ZUBIETA & ] \\
\hline
\end{tabular}




\begin{tabular}{|c|c|c|c|c|c|c|c|}
\hline \multicolumn{2}{|l|}{ BERTIZARANA } & BERASAIN & ] & \multicolumn{2}{|l|}{ VALLE DE LA- } & \multirow{2}{*}{$\begin{array}{l}\text { OLITE } \\
\text { TAFALLA }\end{array}$} & \multirow{2}{*}{$\begin{array}{r}9 \\
20\end{array}$} \\
\hline LEGASA & 1 & LOS PALACIOS & 1 & RRAUNIS & & & \\
\hline NARBARTE & 1 & BEUNZA-LARREA & 1 & ARRUIZ & 1 & MIRANDA & 9 \\
\hline OYEREGUI & 1 & IRIBERR! & 1 & ODERIZ Y MADOZ & 1 & MARCILLA & 4 \\
\hline SANTESTEBAN & 4 & AMALAIN & 1 & ALLI & 1 & LARRAGA & 4 \\
\hline SUMBILLA & 2 & LABASO & 1 & LECUMBERRI & 1 & BERBINZANA & 1 \\
\hline ARANAZ & 2 & EGUILLOR & 1 & IRIBAS & 1 & SANTA CARA & 1 \\
\hline YANCI & 4 & & & ASTIZ & 1 & BEIRE & 2 \\
\hline \multicolumn{2}{|l|}{ VERA DE VIDA- } & \multicolumn{2}{|l|}{ VALLE DE ARAYZ'I } & MUGUIRO & 1 & MILAGRO 24 & 4 \\
\hline SOA & 10 & ARRIBA & 1 & ERRAZQUIN & 1 & PITILLAS & 2 \\
\hline LESACA & 7 & ATALLU & 1 & BARAIBAR & 1 & \multicolumn{2}{|l|}{ MURILLO EL CUEN- } \\
\hline GOIZUETA & 8 & UZTEGUI & 1 & ECHARRI & 2 & $\mathrm{DE}$ & 1 \\
\hline ARANO & 3 & GAINZA & 1 & ALDAZ & 1 & CAPARROSO & 4 \\
\hline \multirow[t]{2}{*}{ VILLAVA } & 2 & AZCARATE 12 & 1 & \multirow{2}{*}{\multicolumn{2}{|c|}{ VALLE DE ARA- }} & FALCES 23 & 21 \\
\hline & & INZA & 1 & & & FUNES & 1 \\
\hline \multicolumn{2}{|l|}{ VALLE DE, ODIETA? } & BETELU & 3 & QULL'16 & & MURILLO EL, & \\
\hline $\begin{array}{l}\text { LATASA } \\
\text { GÜELBENZU }\end{array}$ & 1 & & & ERROZ & 1 & FRUTO & 2 \\
\hline GÜELBENZU & 1 & \multirow{3}{*}{\multicolumn{2}{|c|}{$\begin{array}{l}\text { VALLE DE LA- } \\
\text { RRAUN Y ULZA- } \\
\text { MA13 }\end{array}$}} & EGUIARRETA & 1 & & \\
\hline GASQUE & 1 & & & ECHARREN & I & \multicolumn{2}{|l|}{ VALLE DE ORBA } \\
\hline ANOCIBAR & ] & & & ECAY & 1 & BARASOAIN & 3 \\
\hline CIAURRIZ & 1 & & & ZUAZU & 2 & MENDIVIL & $s$ \\
\hline RIPA & 1 & \multirow{2}{*}{\multicolumn{2}{|c|}{$\begin{array}{l}\text { LARRAINZAR, LIZA- } \\
\text { SO, GORRONZ Y }\end{array}$}} & SATUSTEGUI & 1 & UNZUE & 2 \\
\hline \multirow{2}{*}{ OSTEZ } & \multirow[t]{4}{*}{2} & & & VILLANUEVA & 1 & OLORIZ & ] \\
\hline & & \multirow{3}{*}{\multicolumn{2}{|c|}{$\begin{array}{l}\text { ELSO, URRIZOLA, } \\
\text { CENOZ Y GUEREN- }\end{array}$}} & YABAR & 2 & ECHAGŪE & 1 \\
\hline \multirow{2}{*}{$\begin{array}{l}\text { OLAGÜE Y VALLE } \\
\text { DE ANUE }\end{array}$} & & & & ECHARRI ARANAZ & 4 & MUNARIZQUETA & 1 \\
\hline & & & & IRANETA ${ }^{17}$ & 2 & ERISTAIN & 1 \\
\hline OLAGÜEß & 1 & \multirow{2}{*}{\multicolumn{2}{|c|}{$\begin{array}{l}\text { IRAIZOZ, ALOZ, } \\
\text { ARRAIZ Y BARRIO }\end{array}$}} & HUARTE ARA- & & OLLETA & 1 \\
\hline LANZ & 1 & & & QUIL18 & 2 & PUEYO & 2 \\
\hline & & & & ARRUAZU & 2 & BEZQUIZ & 1 \\
\hline VALLE DE BAZTAN & & DE LUZEEN & l & ARBIZU & 2 & GARINOAIN & 1 \\
\hline ERRAZU & 1 & & & & & ORICOAIN & 3 \\
\hline ARIZCUN & 2 & $\begin{array}{l}\text { VALLE DE IMOZ } \\
\text { STA }\end{array}$ & & MERINDAD DE & & SANSOAIN & 1 \\
\hline AZPILCUETA & $\mathrm{J}$ & LATASA, ERASO, ZA & & TUDELA' & 28 & IRACHETA & 1 \\
\hline ELBETEA & 1 & RRANZ, GOLDARAZ & & TUDELA $^{20}$ & 25 & ARTARIAIN & 1 \\
\hline ELIZONDO & 3 & Y URRIZA & $\mathbf{1}$ & CORELLA & 21 & SAN MARTIN DE & \\
\hline LECAROZ & 1 & ECHALECU & 1 & CASCANTE & 15 & UNS & 3 \\
\hline IRURITA9 & 2 & MUSQUIZ & 1 & CINTRUANIGO & 10 & PERALTA & 11 \\
\hline CIGA & 1 & $\mathrm{OSCOZ}$ & 2 & VILLAFRANCA & 9 & ARTAJONA & 2 \\
\hline ANIZ & 1 & & & VALTIERRA & 6 & UJUE & 2 \\
\hline BERROETA & 1 & VALLE DE BASABU- & & ARGUEDAS & 4 & & \\
\hline ALMANDOZ & 1 & RUA MAYOR'4 & & MONTEAGUDO & 5 & MERINDAD DE & \\
\hline ERRAZU Y ELI- & & YABEN, ICHASO, & & FITERO21 & 8 & SANGÜESA & 298 \\
\hline ZONDO & 1 & UDABE, BERAMEN & & ABLITAS 22 & 6 & & \\
\hline AZPILCUETA Y & & DI Y JALNSARAS & 1 & CARCASTILLO & 3 & SANGŪESA & 29 \\
\hline ELBETEA & 1 & ERVITI Y GAR- & & FONTELLAS & 1 & LUMBIER & 27 \\
\hline MAYA & 2 & ZARON & 1 & BUN̄UEL & 4 & AlBAR & 3 \\
\hline URDAX & 3 & BERRUETE & 1 & FUSTIN̄ANA & 2 & URROZ & 4 \\
\hline ZUGARRAMURDI & 4 & IGOA & 1 & CABANILLAS ${ }^{33}$ & 1 & CASEDA & 1 \\
\hline & & & & MELIDA & 3 & GALLIPIENZO & 4 \\
\hline VALLE DE ATEZ & & VALLE DE BASABU- & & TULEBRAS & 2 & LERGA & 3 \\
\hline BEUNZA & 1 & RUA MENOR & & CORTES & 2 & ESLAVA & 5 \\
\hline ERIZE & 1 & BEINZA-LABAYEN & 2 & MURCHANTE & 1 & SADAR & 5 \\
\hline EGUARAS 10 & 1 & EZCURRA & 1 & & & HUARTE & 4 \\
\hline CIGANDA & 1 & SALDIAS & ] & MERINDAD DE & & TYEBAS & 2 \\
\hline AROSTEGUI & 1 & ERASUN & 1 & OLITE & 124 & BURGUETE & 3 \\
\hline
\end{tabular}

El asociacionismo en la iglesia

Hispania Sacra 50 (1998) 


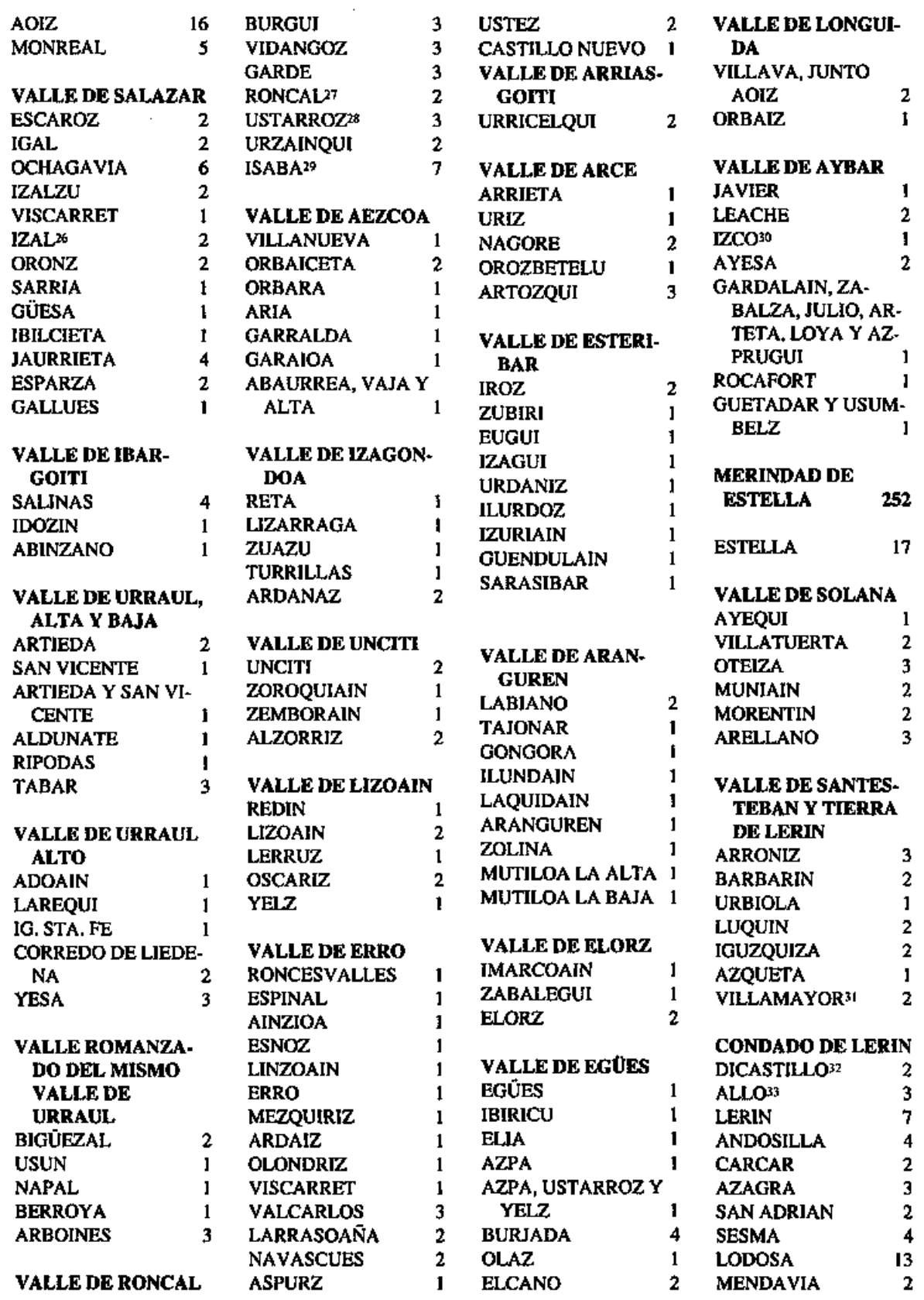




\begin{tabular}{|c|c|c|c|c|c|c|c|}
\hline VALLE DE YERRI ${ }^{34}$ & & VALLE DE GUESA. & & MORIETA & 2 & MUNETA & 2 \\
\hline GORACIN & 1 & $\mathbf{L A} \mathbf{Z}^{\star 6}$ & & ANZIN & 1 & GANUZA & 1 \\
\hline LORCA & 1 & MUNIAIN & 1 & LAGARIA & 2 & LARRION & \\
\hline EGUIARRETA & 1 & LZURBE & 1 & $\mathrm{OCO}$ & 1 & & \\
\hline MURUGARREN & ] & VIDAURRE & 1 & ETAYO & 2 & VALLE DE AGUILA & \\
\hline ARIZALA & 1 & ARGUIÑANO & 1 & & & DESOJO & 2 \\
\hline VILLANUEVA & 1 & $\begin{array}{l}\text { IRUJO } \\
\text { ITURGOYEN }\end{array}$ & 1 & VALLE DE AMES- & & AZUELO & 3 \\
\hline IRUÑELA & 1 & $\begin{array}{l}\text { ITUKGUYEN } \\
\text { MUEZ }\end{array}$ & 1 & ARANARACHE & 1 & TORRALBA & 4 \\
\hline ERAUL & 1 & ESTENOZ, MUZQUI Y & & EULATE & 1 & AGUILAR & 3 \\
\hline RIEZU & 1 & VIGURIA & 1 & LARRAONA & 2 & ESPRONCEDA & 2 \\
\hline LEZAUN & 1 & ARZOZ & 1 & & & MARAÑON & 2 \\
\hline ARIZALETA & 1 & GARISOAIN & ] & VALLE DE LANA & & LAPOBLACION & 3 \\
\hline AZCONA & 1 & IRURRE & 1 & $\begin{array}{l}\text { ULIBARRI, VILORIA, } \\
\text { GASTIAN Y NAR- }\end{array}$ & & $\begin{array}{l}\text { BARRIO/YATRIO DE } \\
\text { STA. MARIA DE }\end{array}$ & \\
\hline VALLE DE MANER & & VALLE DE BERRUE & & QUE & 1 & MLANO & 3 \\
\hline ARGUIÑARIZ & $\mathbf{l}$ & $\mathbf{Z A}$ & & ULIBARRI, GASTIAN & & CABREDO & 4 \\
\hline ECHARREN Y & & PIEDRAMILLERA & 4 & Y NARQUE & 1 & GENEVILLA & 2 \\
\hline GUIRGUILLANO & 2 & MENDAZA & 3 & & & LOS ARCOS 38 & 7 \\
\hline ARTAZU & 1 & ACEDO & 3 & VALLE DE ALLIN & & TORRES & 3 \\
\hline MAÑERU & 2 & ASARTA & 1 & ECHAVARRI & 1 & EL BUSTO & 3 \\
\hline CIRAUQUI & 2 & $\begin{array}{l}\text { MIRAFUENTES } \\
\text { UBAGO }\end{array}$ & $\begin{array}{l}1 \\
1\end{array}$ & $\begin{array}{l}\text { ARTAVIA } \\
\text { AMILLANO }\end{array}$ & 1 & ARMEÑANAS & 5 \\
\hline & & MUES & 2 & OLLOBARREN & 1 & SANSOL & 4 \\
\hline VALLE DE GONI35 & & NAZAR & 2 & EULZ & 1 & VIANA & 0 \\
\hline GOÑI & 1 & SORLADA & 4 & OLLOGOYEN & 1 & BARGOTA & 4 \\
\hline AIZPUN & 1 & COMUN DEL VALLE & & GALDIANO & 2 & BARRIO DE ARAS & 2 \\
\hline AZANZA & ] & & & ARBEIZA & 2 & BARRIO DE LAZGU- & \\
\hline URDANOZ & 1 & VALLE DE EGA & & ZUBIELQUI & 1 & RRIA & $\mathbf{1}$ \\
\hline AIZPUN, URD & & OLEJUA & 1 & ZUFIA & 2 & ZUÑIIGA & 4 \\
\hline AZANZA & 1 & ABAIGAR & 2 & ARAMENDIA & 2 & & \\
\hline
\end{tabular}

\section{NOTAS APÉNDICE}

I Biurrun: existía también una capellanía colativa (Rosario).

2 Adiós: además, función y procesión de S. Cristóbal,

3 Común del Valle: una agrupación comarcal reunía a los sacerdotes (S. Pedro ad víncula).

4 Se menciona fiesta en Zizur menor; la Minerva de Zariquiegui se hal laba suspendida.

5 Lete: una Congregación del Corazón de Jesús estaba extinguida.

6 Ballariain: la Congregación del Corazón de Jesús se hallaba extinguida por la expulsión de los jesuitas.

7 Una agrupación mariana parece congregar a todos los vecinos del valle.

8 Olagüe: se menciona otra asociación sin título.

9 Inurita: además tenía una agrupación de sacerdotes.

10 Eguaras: se cita además la función de S. Pedro.

"Los vecinos del valle se congregaban para la rogativa de Nira. Sra. de Bedayo, S. Miguel y S. Donato.

12 Azcárate: además fiesta y procesión đe S. Fermín.

El asociacionismo en la iglesia

Hispania Sacra 50 (1998) 
13 Otra agrupación parece englobar vecinos de Ilarregui, Elzaburu, Zuarbe y Oroquieta del valle de Basaburua.

14 En Arraras se hacía función a Ntra. Sra. del Rosario.

15 Huici, Gorriti, Aspiroz y Lezaeta organizaban una función alternativamente, sin indicar a quiên se dirigía.

16 En Lacunza hubo tres cofradías, ya extinguidas (S. Blas, S. José y S. Martín).

17 Iraneta: por devoción se celebraba a S. Miguel.

18 Huarte Araquil: también se celebraba función a S. Miguel de Excelsis en su basílica.

19 Se mencionan funciones a S. Blas y S. Bartolomé en Rivaforada y a Sta. Bárbara en Barillas.

20 Tudela: se menciona también una cofradía extinguida (Sta. Margarita).

21 Fitero: se celebra también voto a Ntra. Sra. de Yerga, en Castilla.

22 Ablitas: además sendos votos-rogativas a Ntra. Sra. del Moncayo y a Ntra. Sra. del Camino.

23 Cabanillas: los vecinos peregrinaban a la basílica de Sta. Margarita de las Bárdenas.

24 Milagro: se citan también varias fiestas.

25 Falces: había además una cofradía en trámite de fundación (Nura. Sra. đe Nieva).

26 lzal: se citan también varias fiestas.

27 Roncal: había también una agrupación de ganadéros.

28 Ustarroz: asimismo, otra agrupación de ganaderos.

29 Isaba: aparte, una asociación de ganaderos, con S. Urbicio como patrón.

30 Izco: además celebraba fiesta a su patrón, S. Miguel.

31 Villamayor: los vecinos hacían procesión a S. Pedro Mártir en la basílica de Monjardín.

32 Dicastillo: otra antigua cofradía se había agregado al hospital (S. Julián y Sta. Basilisa),

33 Allo: además, fiesta patronal a Sta. María Magdalena.

34 Dos agrupaciones sin título debían existir, una en Ziruquain y otra en Igar, además de la Hospitalidad de Abarzuza.

35 En Munarriz existía una capellanía de Ntra. Sra. del Rosario.

36 En Salinas de Oro una cofradía de S. Pedro se había agregado a la sacristía; en Guembe se cita una capellanía de $\mathbf{S}$. Bartolorné.

37 En el Valle de Amescoa la Baja sólo se reseña la devoción general a las Animas.

38 Los Arcos: se menciona también el hospital de Sta. Brígida y el culto a S. Crispín por los zapateros de obra prima. 